ارزيابى تأثير سطوح مختلف كم آبيارى و خشكى موضعى ريشه بر عملكرد و بهرهورى مصرف آب ذرت دانهاى در منطقه حاجى آباد

\author{
مهدى شهسوارى گوغرى'، عباس رضايى استخروييه"، محسن ايراندوست' و على نشاط'

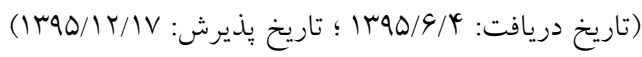

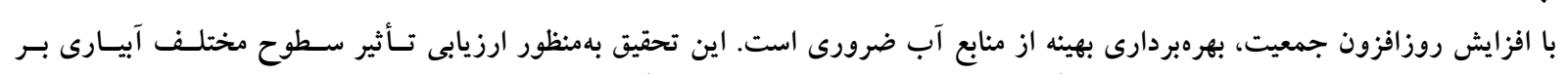

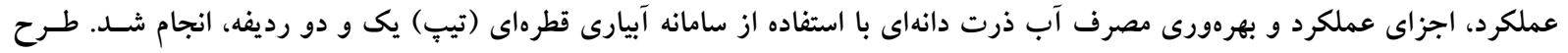

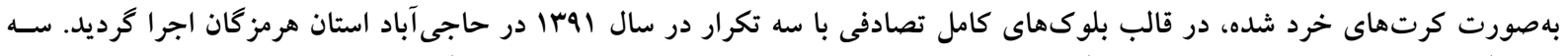

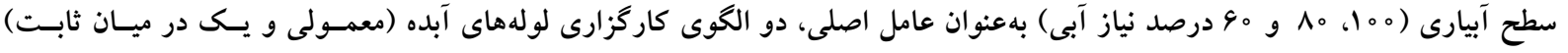

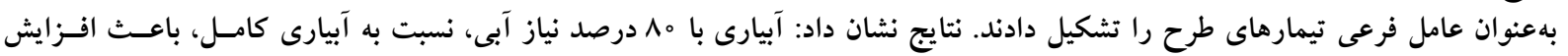

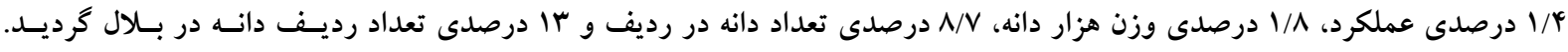

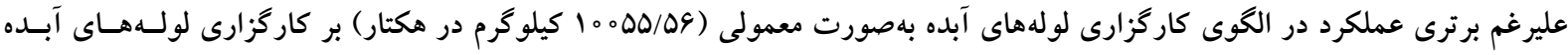

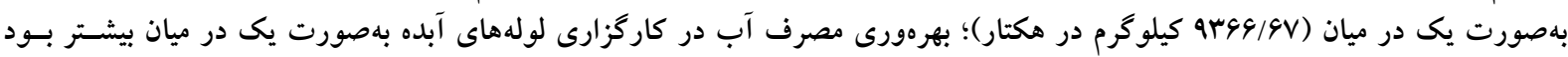

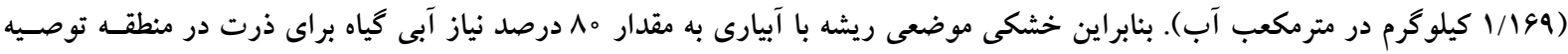

وازههاى كليدى: آبيارى قطرهاى، اجزاى عملكرد، بهينه سازى مصرف آب، خشكى موضعى ريشه، لولههاى تيب

\footnotetext{
ا. كروه كشاروزى، دانشكده فنى، دانشخاه آزاد اسلامى واحد كرمان، كرمان، ايران

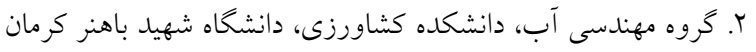

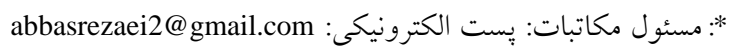




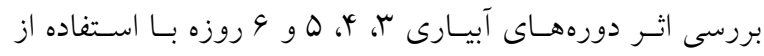

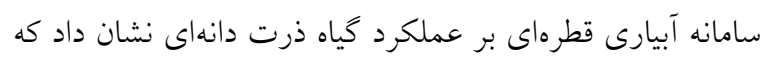

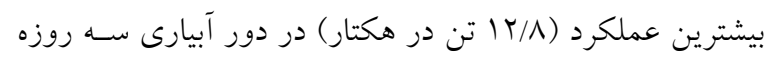

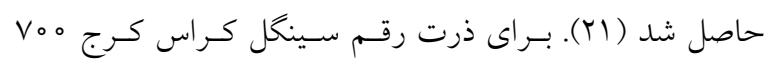

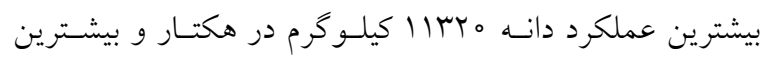

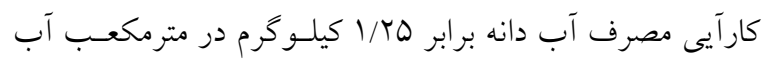

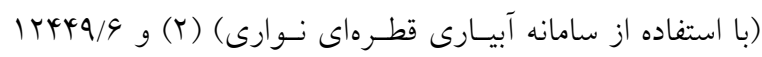

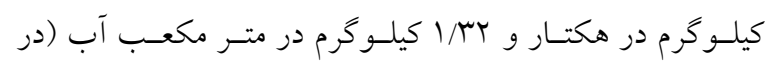

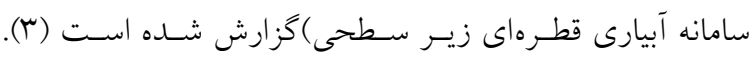

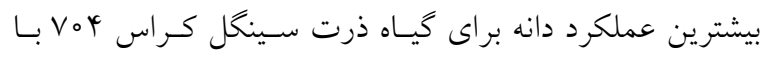
اعمال روش خشكى موضعى ريشه در مرحله رشد زايشى برابر

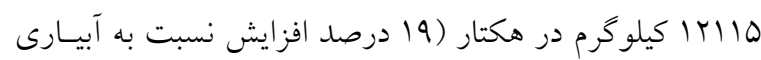

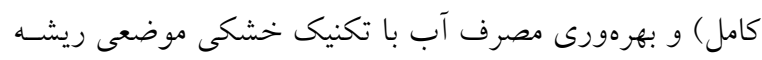

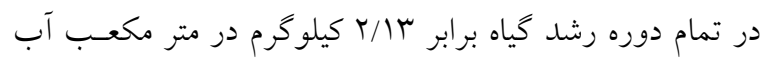

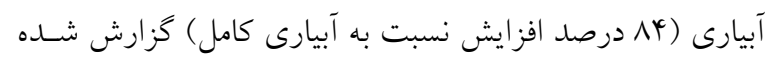

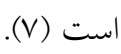

بهرهبردارى بىرويه از منابع آب در اسـتان هرمزگـان كـاملاً.

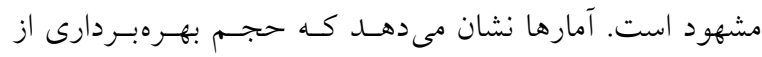

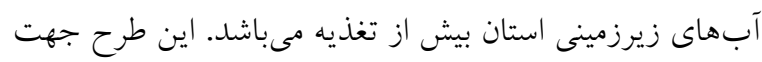

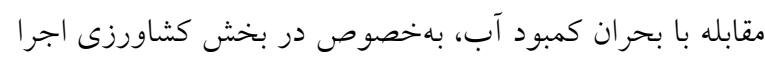

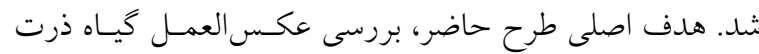
در برابر كم آبيارى سنتى و خشكى موضسعى ريشـه در سـامانه

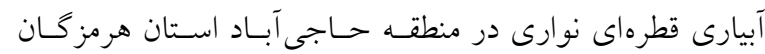
مىباشد.

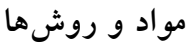

ايـن تحقيـق در سـال اهَا در مزرعـه تحقيقـات كشـاورزى، در

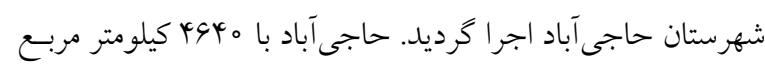

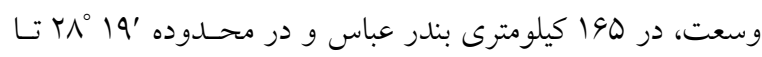

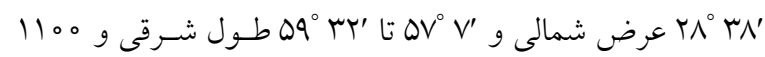

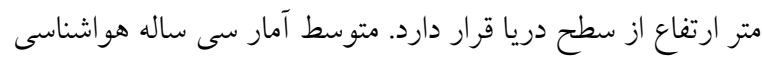

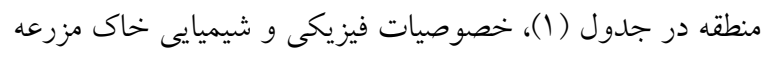

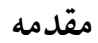

سامانهاى نوين آبيارى، علاوه بر كاهش مصـرف آب، افـزايش

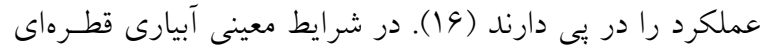

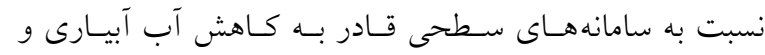

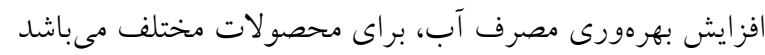

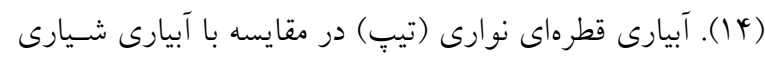

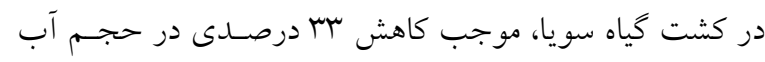

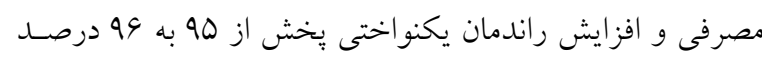

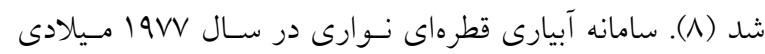

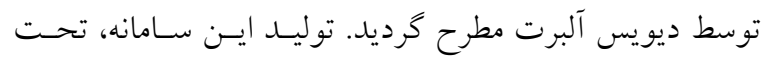

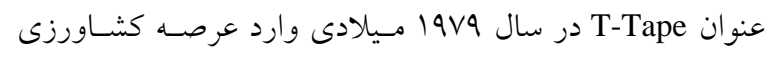

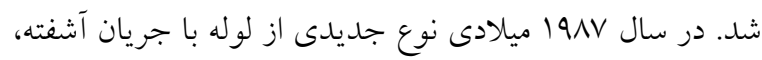

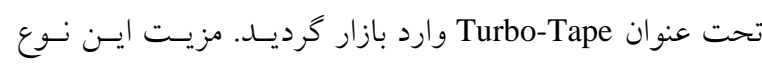

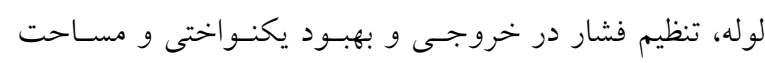

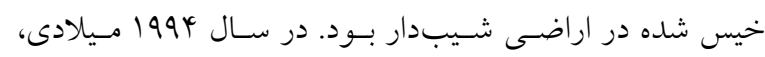

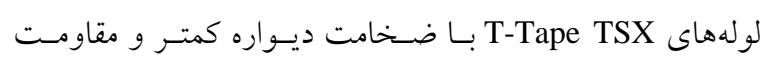

$$
\text { بيشتر بيشنهاد كرديد. }
$$

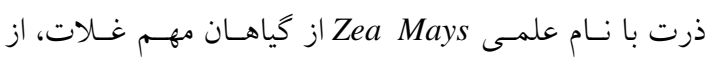

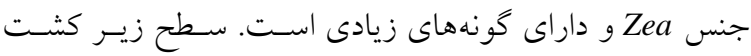

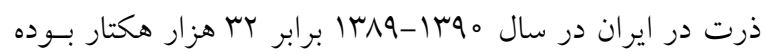

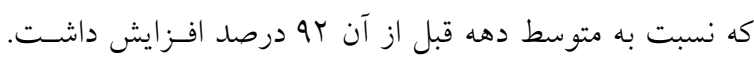
در ه سال اخير كشت ذرت در كشور افزايش يافته است. توليـد

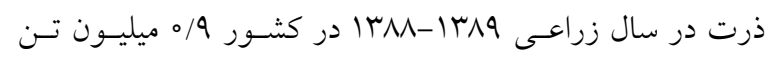

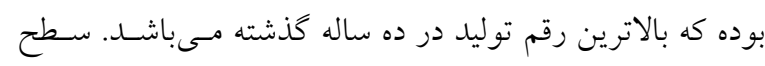

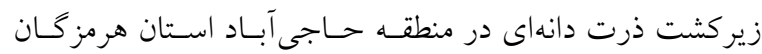
ه هQ0 هكتار و داراى متوسط توليد V تن در هكتار مىباشد.

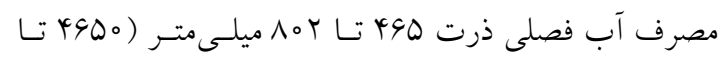

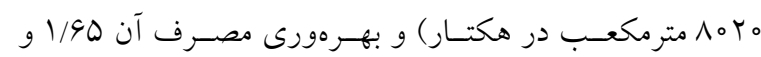

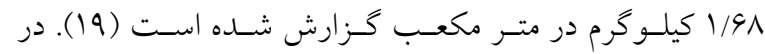

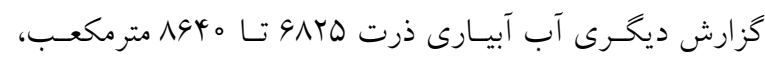

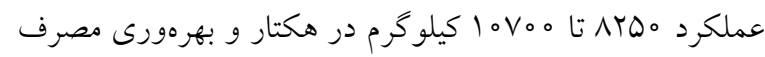

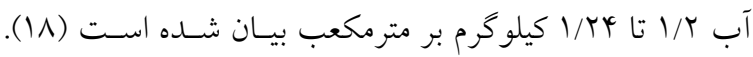


ارزيابى تأثير سطوح مختلف كمآبيارى و خشكى موضعى ريشه بر عملكرد ....

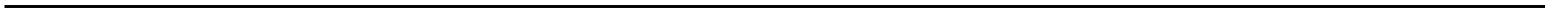

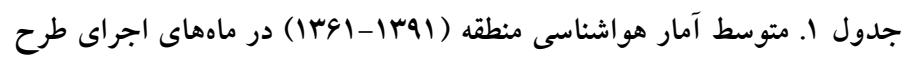

\begin{tabular}{|c|c|c|c|c|c|c|}
\hline \multirow{2}{*}{ مالانه } & \multicolumn{5}{|c|}{ ماههاى سال } & \multirow{2}{*}{ لِّارامترها } \\
\hline & مهر & شهريور & مرداد & تير & خرداد & \\
\hline YN/D & $\mu_{0}$ & TV & $r q / r$ & 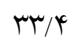 & rr & ميانكين دما (م) \\
\hline$\wedge$ & 0 & $r / \Lambda$ & $I T / V$ & $V / V$ & 。 & بارندگى (mm) \\
\hline r。 & $r 9 / 0$ & rq & M & $r 4 / 9$ & $r T / I$ & رطوبت نسبى (\%) \\
\hline
\end{tabular}

جدول Y. نتايج تجزيه فيزيكى و شيميايى خاك مزرعه

\begin{tabular}{|c|c|c|c|c|c|c|c|c|c|c|c|c|c|}
\hline \multirow{2}{*}{$\begin{array}{c}\text { EC } \\
\left(\mathrm{dS} \mathrm{m}^{-1}\right)\end{array}$} & \multirow{2}{*}{$\mathrm{pH}$} & \multirow{2}{*}{ SAR } & \multicolumn{6}{|c|}{ آنيونها و كاتيونهاى محلول (meq L-1) } & \multirow{2}{*}{ بافت } & \multicolumn{3}{|c|}{ اجزاى خاى (.) } & \multirow{2}{*}{$\begin{array}{c}\text { عمق خاك } \\
\quad(\mathrm{cm})\end{array}$} \\
\hline & & & $\mathrm{Ca}^{+r}$ & $\mathrm{Mg}^{+r}$ & $\mathrm{Na}^{+}$ & $\mathrm{Cl}^{-}$ & $\mathrm{HCO}_{r}^{-}$ & $\mathrm{SO}_{\varphi}^{-r}$ & & شن & 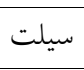 & رس & \\
\hline $0 / \wedge \Delta$ & $\wedge$ & $1 / 9$ & 10 & 10 & $Q / T$ & $\wedge$ & $r / \Lambda$ & N/9 & S-C-L & ir & $\Delta \wedge$ & rq & $0-r_{0}$ \\
\hline$\circ / \Lambda$ & $V / 4$ & $r / 1$ & 9 & $r$ & $\varphi / \Lambda$ & $r$ & $r$ & $V / q$ & S-C-L & IV & 01 & rt & ro-so \\
\hline$\circ / \mathrm{NA}$ & $V / 0$ & $1 / 1$ & r & 10 & $r / 9$ & r & r & $0 / \omega$ & S-C & r & 09 & rV & $90-90$ \\
\hline
\end{tabular}

جدول r. خصوصيات شيميايى آب آبيارى

\begin{tabular}{|c|c|c|c|c|c|c|c|c|c|c|c|}
\hline \multirow{2}{*}{$\mathrm{pH}$} & \multirow{2}{*}{$\begin{array}{c}\mathrm{EC} \\
\left(\mathrm{dS} \mathrm{m}^{-1}\right)\end{array}$} & \multicolumn{4}{|c|}{ آنيونها (meq L'1) } & \multicolumn{6}{|c|}{ كاتيونها (meq L') } \\
\hline & & $\mathrm{CO}_{r}^{-r}$ & $\mathrm{HCO}_{r-}^{-}$ & $\mathrm{Cl}^{-}$ & $\mathrm{SO}_{4}^{-r}$ & $\mathrm{Mg}^{+r}$ & $\mathrm{Ca}^{+r}$ & $\mathrm{~K}^{+}$ & $\mathrm{Na}^{+}$ & $\mathrm{Fe}^{+r}$ & $\mathrm{Mn}^{+r}$ \\
\hline$V / \mathrm{I}$ & $1 / \mathrm{V}$ & - & $r / r$ & $\Delta / r$ & $T / 4$ & $9 / 1$ & $N / \varphi^{4}$ & - & $\mathrm{v}$ & $\circ \% \vee \wedge$ & $0 / 014$ \\
\hline
\end{tabular}

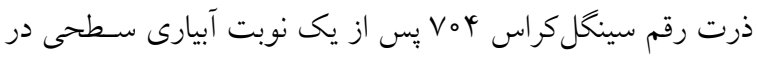

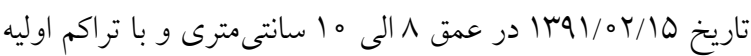

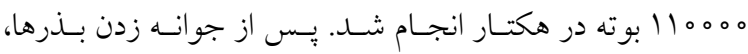

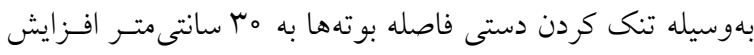

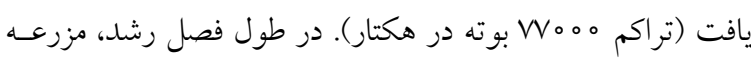

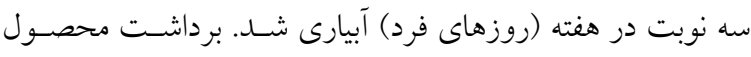

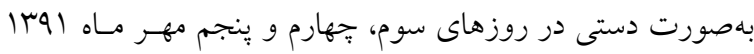

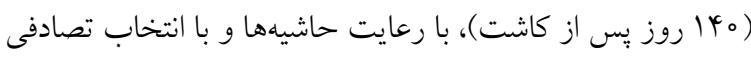

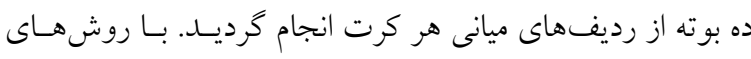

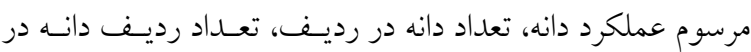
بلال و وزن هزار دانه براى هر تيمار تعيين گرديد.

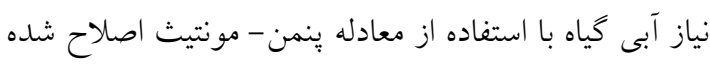

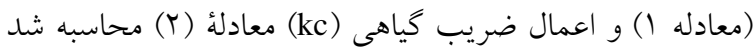

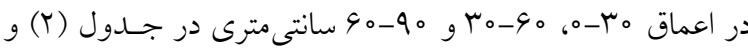

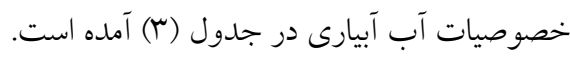

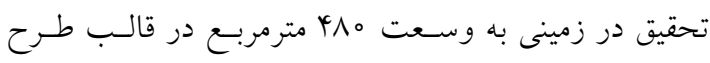
بلوكهاى كامل تصادفى بهصورت كرتهاى خرد شده (اسبليت

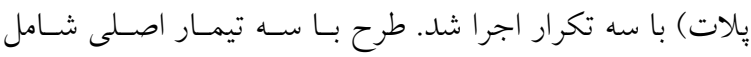

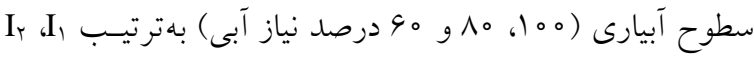

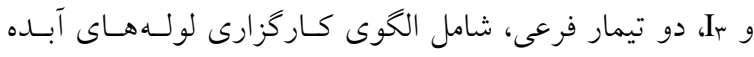

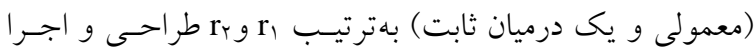
كرديد. جانمايى طرح در شكل (1) آمده است.

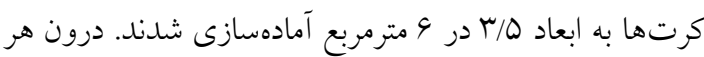

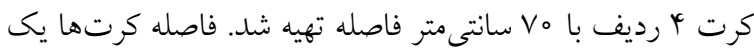

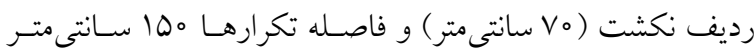

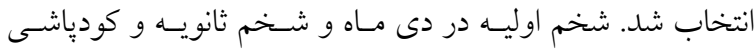

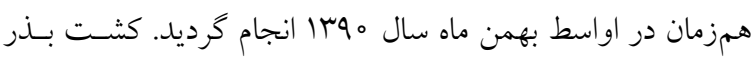




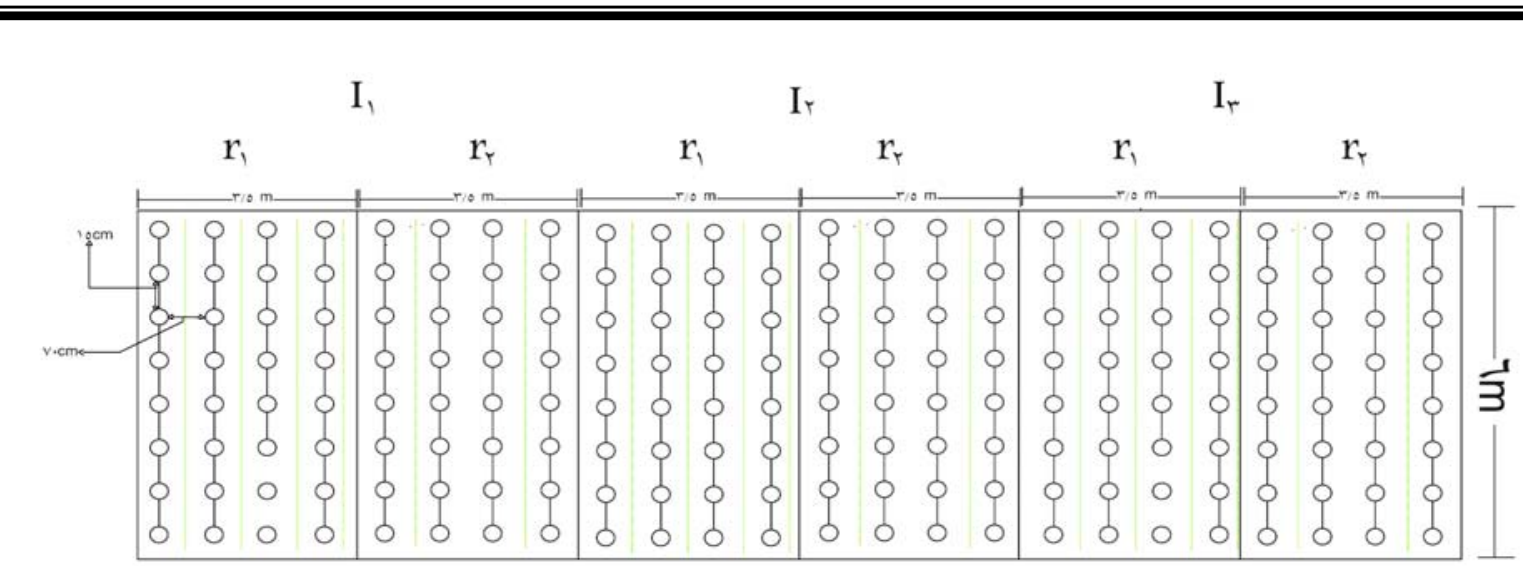

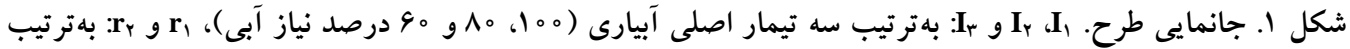

الكوى كارگزارى لولههاى آبده (معمولى و يك درميان ثابت)

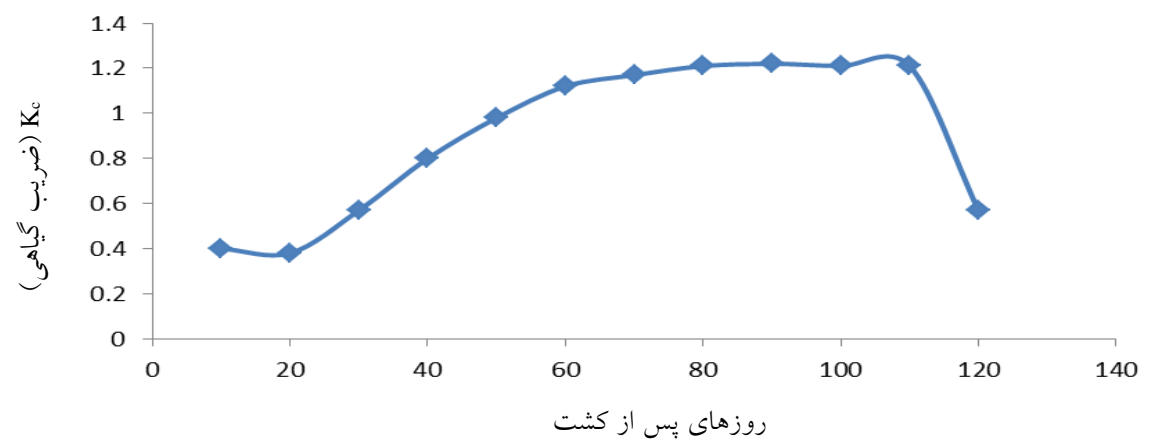

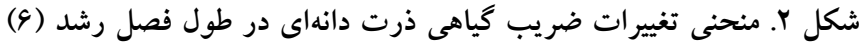

صرف نظر بوده و فقط تعرق مد نظر قـرار مسى گيـرد. بنـابراين در

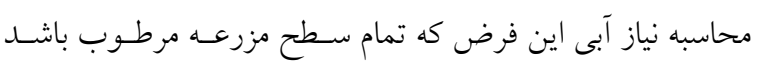
تعديل مىشود. تعرق روزانه كياه در آبيارى قطرهاى، تابعى از سطح

سايه|نداز كياه بوده و از معادله (r) محاسبه مىشود (11). $\mathrm{Td}=\mathrm{ET}_{\text {crop }}\left[\circ /(\mathrm{Pd})^{\circ / \Delta}\right]$

در اين معادله: Td: نياز آبى روزانه در آبيـارى قطرهاى، ET تبخير و تعرق گياه و Pd: درصد سطح سايه انداز گياه مىباشد. بــا داشـتن اطلاعــات روزانـه هواشناسـى و بــا اسـتفاده از معادلات (او r r) نياز آبى روزانه گياه محاسبه و با توجه به دور

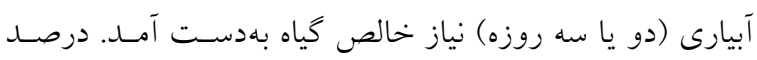
سطح سايهانداز، نسبت سايه گياه در ظهر به سطح زمين متعلـق به هر كياه است. انــازه كيـرىهـاى لازم بـراى محاسـبه سـطح

$$
\begin{aligned}
& \mathrm{ET}_{\mathrm{O}}=\frac{\diamond / \kappa_{\circ} \Delta \Delta\left(\mathrm{R}_{\mathrm{n}}-\mathrm{G}\right)}{\Delta+\gamma\left(1+\circ / \mu \mathrm{U}_{\mathrm{r}}\right)}+ \\
& \frac{[\wedge \vee \gamma /(T+r \vee r)] U_{r}\left(e_{a}-e_{d}\right)}{\Delta+\gamma\left(1+\circ / \mu r U_{r}\right)}
\end{aligned}
$$

$\mathrm{ET}_{\text {crop }}=\mathrm{K}_{\mathrm{c}}\left(\mathrm{ET}_{\mathrm{o}}\right)$

در اين معادلات: ETO: تبخير و تعرق گياه مرجع (mm day ${ }^{-1}$ (mm)،

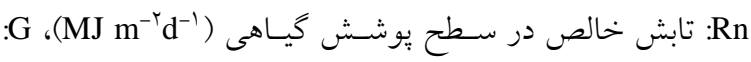

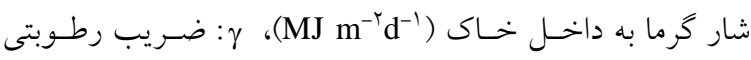

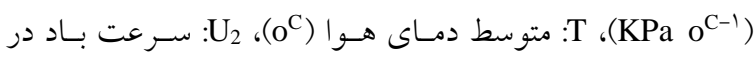
ارتفاع دو مترى از سطح زمين (m sºd)، (ea-ed): كمبـود فشـار بخار هوا (KPa)، ETcrop: تبخير و تعرق گياه مورد نظر و و ضريب گياهى شكل (Y) مى باشد. در آبيارى قطرهاى، تبخير از سطح خاى مرطوب ناجيز و قابل 
ارزيابى تأثير سطوح مختلف كم آبيارى و خشكى موضعى ريشه بر عملكرد ...

جدول r. خلاصه تجزيه واريانس صفات اندازهيرى شده طرح

\begin{tabular}{|c|c|c|c|c|c|c|}
\hline تعداد رديف دانه & تعداد دانه در & وزن هزار دانه & مصرف آب & عملكرد & آزادى درجه & تغنير \\
\hline $\mid V / D 9$ & $r_{0 / 009}$ & $49 / 19$ & \%OOT & $1000 \Delta \Delta \Delta / \Delta 9$ & $r$ & تكرار Rep \\
\hline$V r / V r^{* *}$ & $\mid r V / N r^{* *}$ & TVQS $100^{* *}$ & $0 / / k Y^{* *}$ & 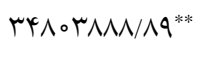 & r & Aيبارى A \\
\hline $0 / 94$ & $\circ / V Y$ & YTr & $0 / 001$ & MTYTY/TY & $r$ & خطا (E1) \\
\hline $0 \circ / 00^{* *}$ & $100 / Y^{* *}$ & $\Delta V N / \circ 0^{* *}$ & $0 / \circ Y Q^{* *}$ & $r \mid r \Delta \Delta \Delta \Delta \Delta \Delta / \Delta q^{* *}$ & 1 & كاركزارىB \\
\hline $1 / / V^{n s}$ & $0 / 0 \varphi^{\mathrm{ns}}$ & $\mid N / I V^{* *}$ & $\circ / \circ \circ 1^{\mathrm{ns}}$ & $111111 / 11^{\mathrm{ns}}$ & r & $\mathrm{A} \times \mathrm{B}$ \\
\hline $0 / T \Lambda$ & $0 / 911$ & $\circ / \mathrm{VA}$ & $\%$ & ITVVV/VA & 4 & خطا (E2) \\
\hline
\end{tabular}

ns : بهترتيب معنى دار در سطح احتمال يكى درصد و غير معنىدار

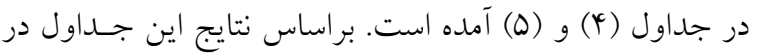
مورد صفات مورد نظر بحث مى شود.

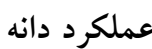

نتايج تجزيه واريانس نشان داد، تأثير آبيارى و الحوى كارگزارى لولهها بر عملكرد دانه در سطح يك درصد معنسى دار؛ امـا تأثير

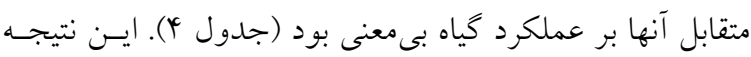

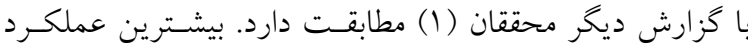

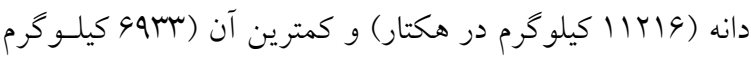

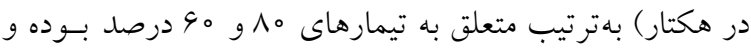

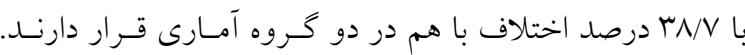

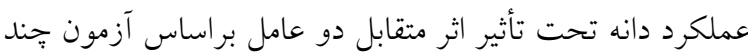
دامنهاى دانكن در سطح ينج درصد، داراى اخستلاف معنسى دارى لئس نمىباشند؛ اما بيشترين عملكـرد دانسه در كياهـان تحـت تيمـار

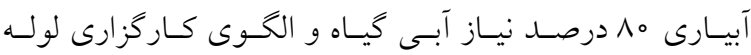
بهورت معمـولى و كمتـرين آن در كياهـان تحـت تيمـار درصد نياز آبى كياه و الكوى كارگزارى يكى در ميان اتفاق افتاد. كاهش عملكرد در گياهان تحت تيمار آبيارى كامـل را بـه ايسن صورت مىتوان توجيه كرد: آبيارى بيش از حد نياز ذرت علاوه

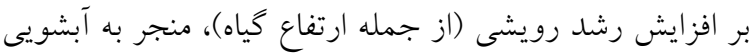
مواد غذايى از ناحيه ريشه و در نتيجه كاهش عملكرد مى شـود.

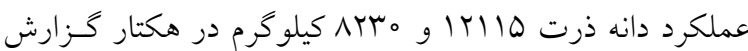

سايهانداز در مراحل مختلف رشد در مزرعه انجـام شـد. بـا در

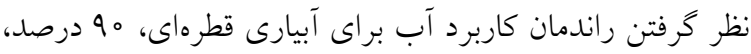
فاصله بين رديفها، فاصله بين بوتهها، دور آبيارى و تعداد بوته

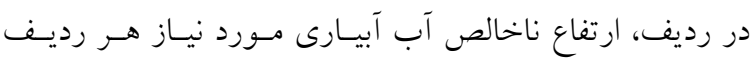

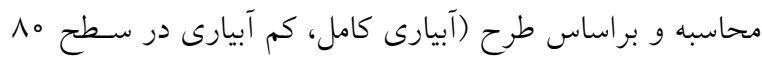

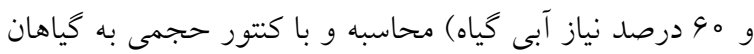

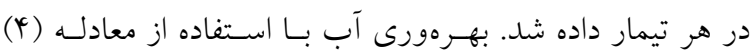
محاسبه شد.

$\mathrm{WP}=\frac{\mathrm{Y}_{\mathrm{T}}}{\mathrm{V}_{\mathrm{T}}}$

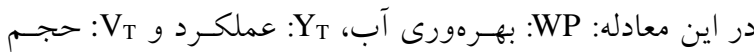
آب مصرفى مىباشد.

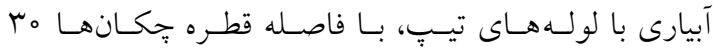

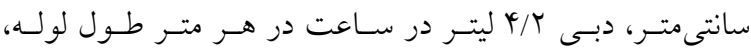

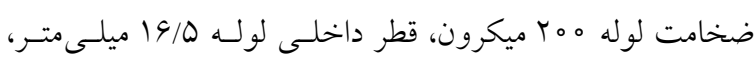

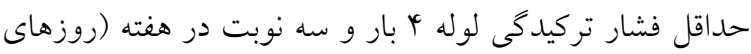

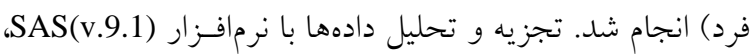

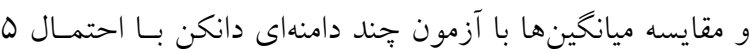

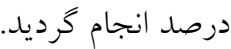

\section{نت ايج و بحث} نتايج تجزيه واريانس و مقايسه ميانخين صفات اندازهيرى شده 
نشر يه علوم آب و خاك (علوم و فنون كشاورزى و منابع طبيعى) / سال بيست و دو / شماره يك/ بهار IrqV

\begin{tabular}{|c|c|c|c|c|c|c|}
\hline تعداد رديف & تعداد دانه & وزن دزان & 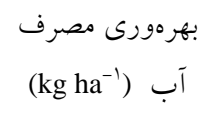 & حجم آب مصرفى & $\begin{array}{c}\text { عملكرد } \\
\left(\mathrm{kg} \mathrm{ha}^{-1}\right)\end{array}$ & تيمارها \\
\hline $1 / / \circ \circ b$ & $49 / 1 V^{b}$ & $\mu \circ \Delta / \Delta \circ b$ & $1 / 01 V^{b}$ & l. $/ 99 / \mathrm{V} \mathrm{ra}^{\mathrm{a}}$ & ا & $\mathrm{I}_{1}$ \\
\hline$r I / l V^{a}$ & & س & $1 / \mu \circ f^{a}$ & $\Lambda \varepsilon_{0} \mid / N y^{c b}$ & $\|r\| 9 / 9$ a & $\mathrm{I}_{2}$ \\
\hline $\mid \psi / 1 V^{c}$ & c س c & YMM/OOC & $1 / 09 V^{b}$ & $949 V / 94 \mathrm{C}$ & b سת/אח9 b & $\mathrm{I}_{3}$ \\
\hline $\mathrm{IV} / \mathrm{VV}$ & $r Q / 4 \varphi$ & $\mu_{0} \mid / \mu t$ & $1 / 1 \mu$ & $\wedge \Delta 94 / 91$ & $9 V 11 / 1 r$ & ميانگين \\
\hline $19 / 4 y$ a & 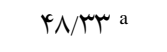 & $\mu \mid r / g V a$ & $1 / \circ \wedge q^{b}$ & arr/VQa & $1 \circ \circ \Delta Q / \Delta \varphi \mathrm{a}$ & $\mathrm{r}_{1}$ \\
\hline $19 / 11 \mathrm{~b}$ & $C Y / D G b$ & $r q \circ / T r^{b}$ & $1 / 199$ a & $\Lambda \cdot \mid r / D Y^{c a}$ & $9494 / 9 \mathrm{~V} \mathrm{~b}$ & $\mathrm{r}_{2}$ \\
\hline $\mathrm{IV} / \mathrm{VV}$ & $r Q / 4 F$ & $\mu_{0} / / 4 t$ & $1 / 1 \pi$ & $1094 / 91$ & $9 V 11 / 1 r$ & ميانگين \\
\hline$r \circ / 0^{a}$ & $<q / 0 \circ a$ & rIT/OOb & $\circ / 9 \vee \wedge{ }^{a}$ & $11909 / 44$ a & $11400 / 00 a$ & $\mathrm{I}_{1} \mathrm{r}_{1}$ \\
\hline $19 / 00^{a}$ & a זת/זא & $r 99 / 00 \mathrm{~d}$ & $1 / \circ \Delta \Delta^{a}$ & $10010 / \wedge^{a}$ & $10099 / 9 \mathrm{~V}$ a & $\mathrm{I}_{1} \mathrm{r}_{2}$ \\
\hline$T r / 0^{a}$ & $\Delta r / 9 \mathrm{~V}$ a & $M \mathrm{~V} / \mathrm{gVa}$ & $1 / T G 4$ a & $9100 / N k^{b}$ & $11094 / 9 \mathrm{Va}$ & $\mathrm{I}_{2} \mathrm{r}_{1}$ \\
\hline 19/4 س a & $\mid 4 / 100$ a & ror/o。c & $1 / N Y Q^{a}$ & $\Lambda \circ \vee q / \mu^{b}$ & $10199 / 9 \mathrm{Va}$ & $\mathrm{I}_{2} \mathrm{r}_{2}$ \\
\hline 10/rسa & a מת/א a & TVQ/०。e & 1/0YGa & $V 01 N / 19 \mathrm{c}$ & $V Y \circ \circ / 9 \mathrm{~V}$ a & $\mathrm{I}_{3} \mathrm{r}_{1}$ \\
\hline $1 \pi / 00^{a}$ & & $r G V / G V \mathrm{f}$ & $1 / 1 \circ \wedge^{a}$ & $9019 / T K^{c C}$ & $9999100 \mathrm{a}$ & $\mathrm{I}_{3} \mathrm{r}_{2}$ \\
\hline IV/VV & $r Q / F Y$ & $\mu_{0} \mid / 4 t$ & I/T & VASQ/YT & $9 V 11 / 1 T$ & ميانخين \\
\hline
\end{tabular}

در هر ستون، ميانكينها با حروف مشترك، براساس آزمون جند دامنهاى دانكن در سطح ه درصد، اختلاف معنى دار با هم ندارند

\section{بهرهورى مصرف آب}

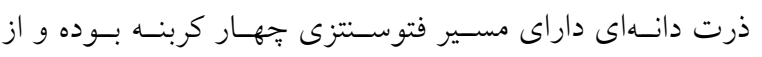

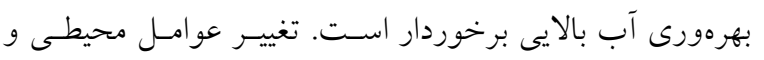

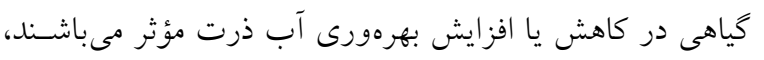

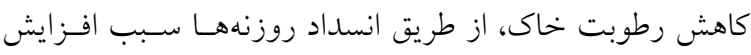

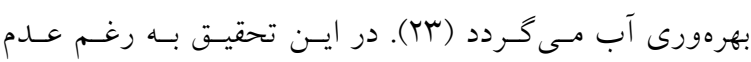

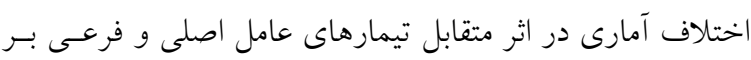

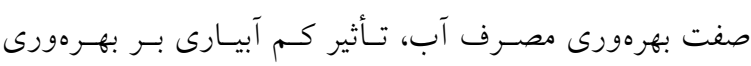
مصرف آب در سطح يكى درصد معنى دار مىباشـــ (جــدول ه).

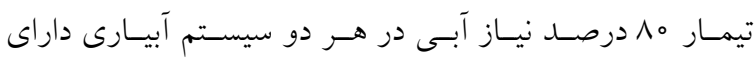
بهرهورى مصرف آب بهتـرى نسـبت بـه دو تيمـار ديخـر بـود.

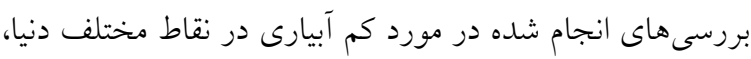

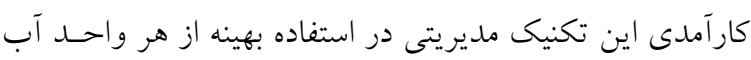

مصرفى و افزايش سود خالص را نشان مى دهد (F) أ).

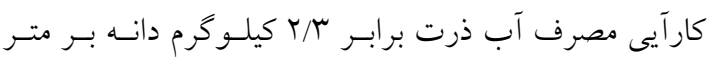

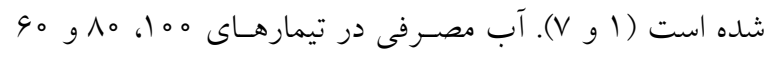

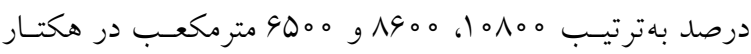

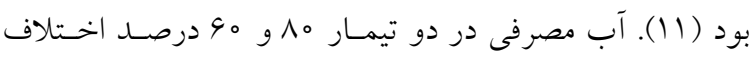

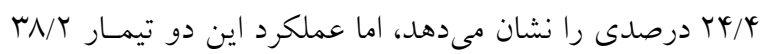

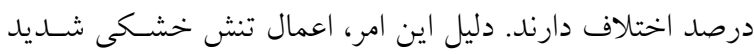

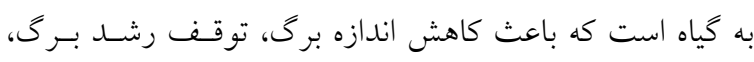

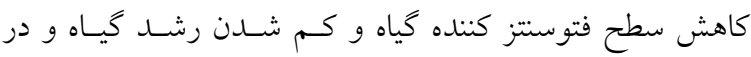

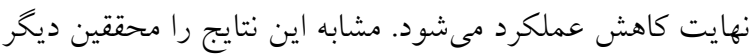

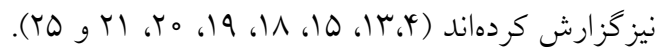
مقايسه ميانخين عملكرد نشان مىدهد كه الخوى كـارگزارى

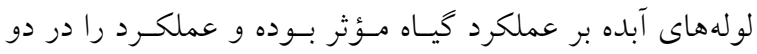

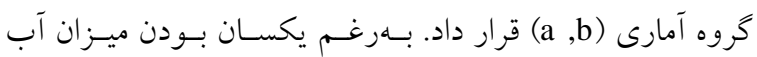

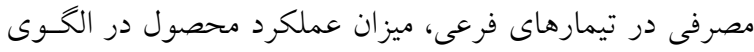

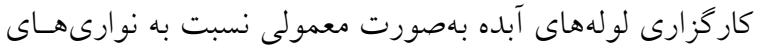
يك در ميان 9/1 9 درصد بيشتر مى باشد. بهورس 
در بيى خواهد داشت (Y) (1). در اين تحقيق اثر تيمارهاى آبيـارى و الكوى كاركزارى بر صفت مذكور معنى دار اما اثر متقابل ايسن

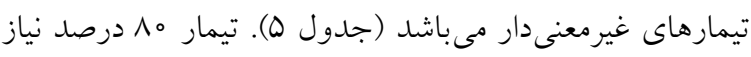

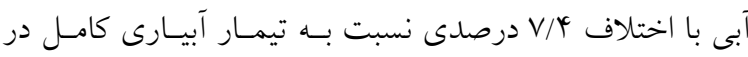

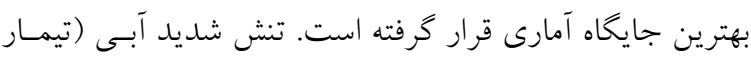

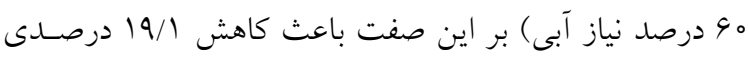

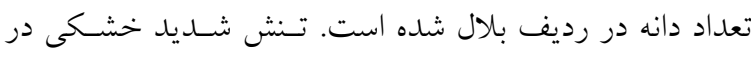

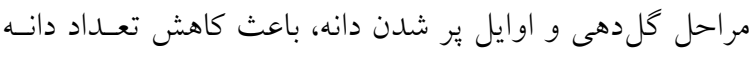

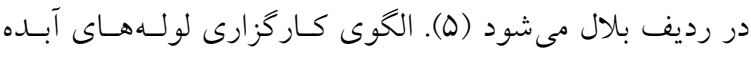

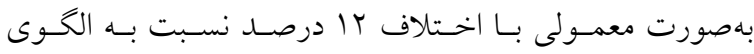

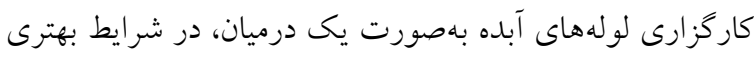

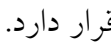

تعداد رديف دانه در بلال

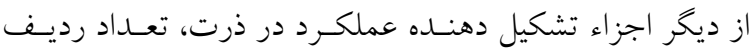
دانه در بلال است، كه بهعنوان يك صفت ارثى كمتر تحت تأثير شرايط محيطى قرار مى گيرد و به رقم كشت شـده بسـتخى دارد

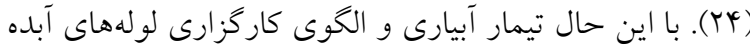
بر صفت فوق اثر معنىدارى داشتند. مقايسه ميانخين اين صـفت

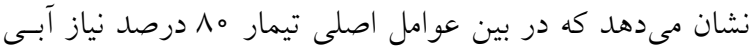
و در بين عوامل فرعى تيمار الكوى كـاركزارى لولـهـــاى آبـــه بهصورت معمولى داراى بهترين وضعيت مىباشند.

\section{نتيجه گيرى}

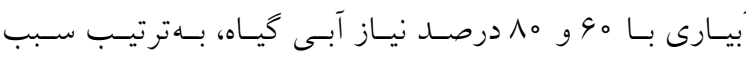

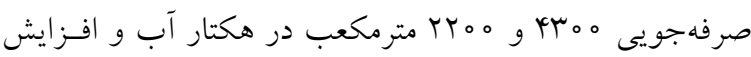

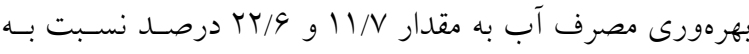

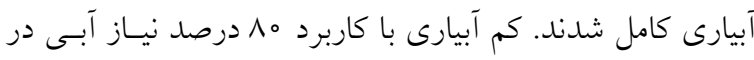

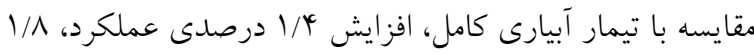
درصدى وزن هزار دانه، N/V درصدى تعداد دانه در هر رديف و ترائ

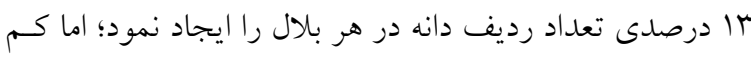

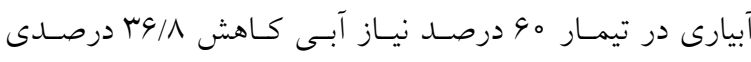

مكعب در آبيارى با م1 در صد نيـاز آبسى و بـا سـامانه آبيـارى قطرهاى نوارى گزارش شده است (9). در يك تحقيق، بهرهورى

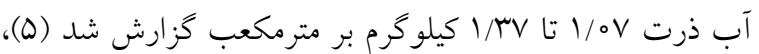

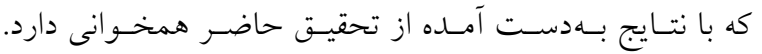

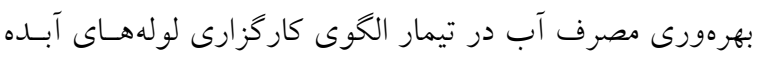

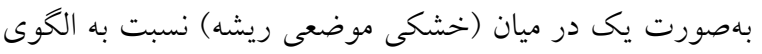

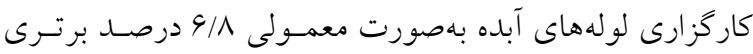
داشت.

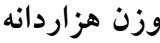
براساس نتايج تجزيه واريانس، تأثير آبيارى، الخـــى كاركـذارى

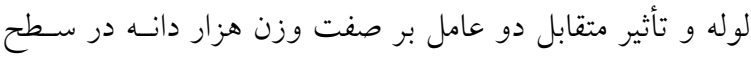

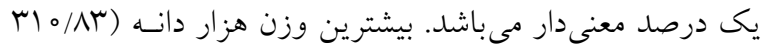

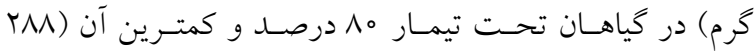

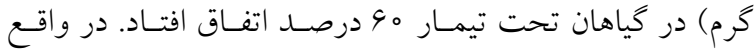
اندازه دانههاى ذرت در گياهان تحت تيمار م1 درصد نسبت به

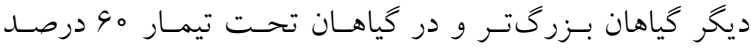
كوجكتر بود. بنـابراين مسىتـوان كفـت تـش رطـوبتى باعـث كوجى شدن دانههاى ذرت شده است. محققين مهمترين عامل

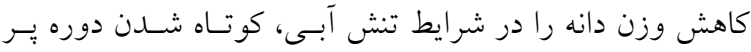
شدن دانه مى دانند. در اين شرايط عرضه مواد ״ـرورده بــه كيـاه

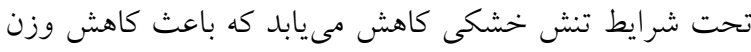

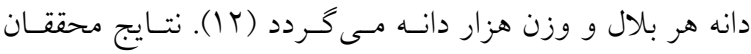

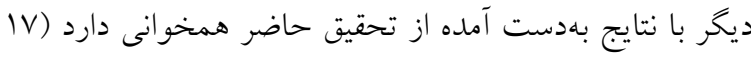

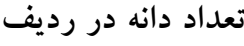

يكى از اجزاء مهم عملكرد هيبريدهاى تـكبلالـه ذرت، تعسداد

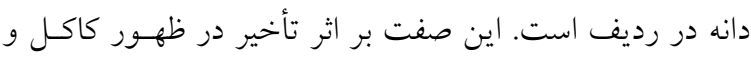
يا سقط جنين در اثر كمبود هيدراتهاى كربن كاهش مسيابــ. تنشهاى محيطى باعث كو تاه شــن دوره تمـايز سـنبلجه و در نتيجه كاهش تعداد سنبلجه در سنبله كشته و كاهش عملكرد را 
ريشه، بهرهورى مصرف آب در الكوى كارگزارى لولههاى آبــده

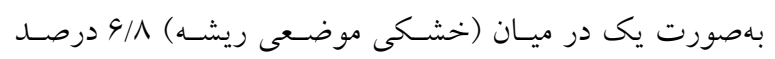

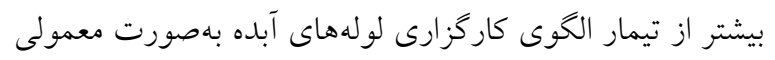

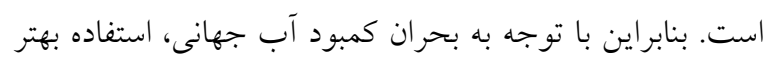

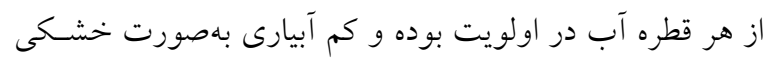

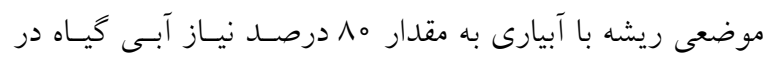
منطقه توصيه مى مودود.

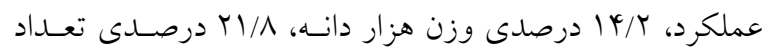

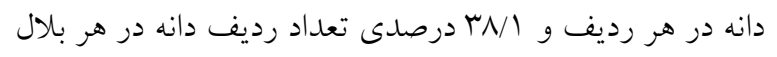

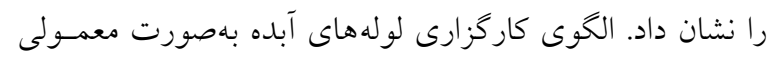

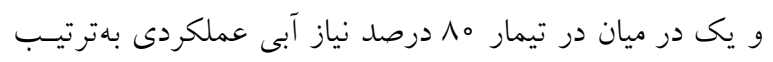

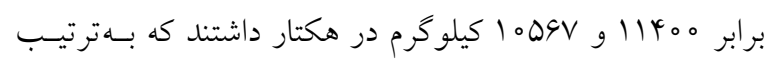

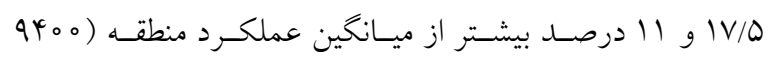

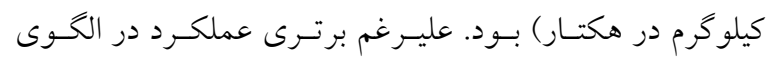

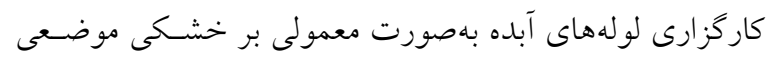

\section{منابع مورد استفاده}

ا. ا اخوان، ك. و م. ر. شيرى. MM آ. بررسى سطوح مختلف آب و آرايش كاشت ذرت دانهاى به روش آبيارى نوارى قطرهاى در منطقـه

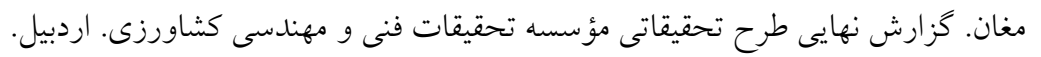

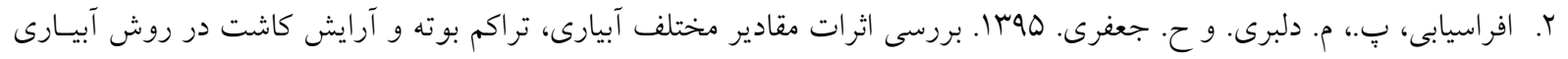

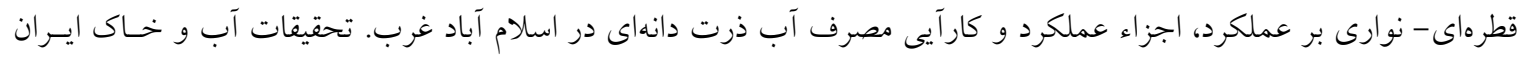

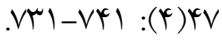

r. افشار، ه. و س. ح. صدر قاين. rوسا. اثر سطوح مختلف آب، تراكم بوته و آرايش كاشت بر بهرهورى آب ذرت دانهاى در سيستم

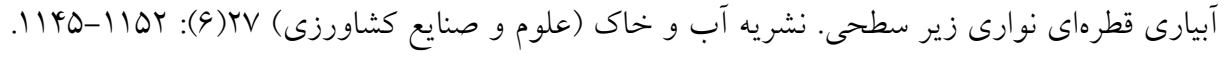

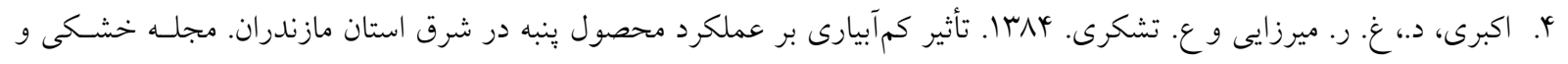

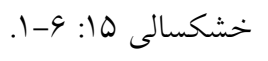

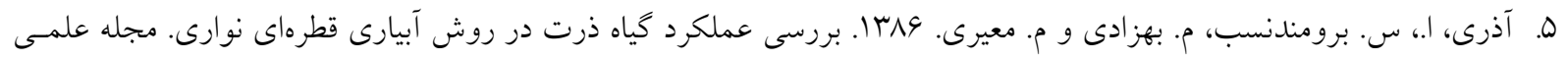

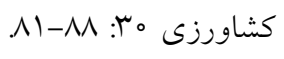

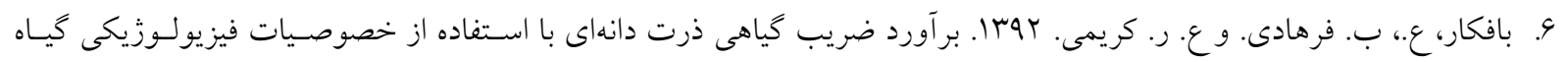

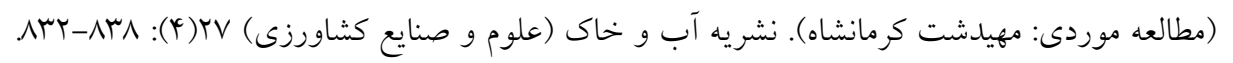

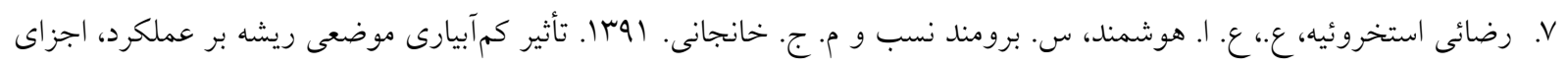

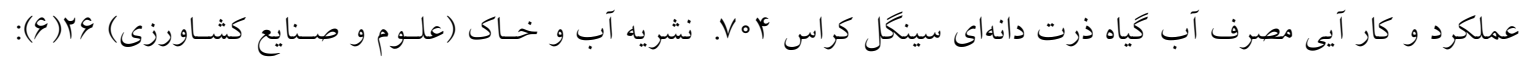
$|Q T|-|Q T|$

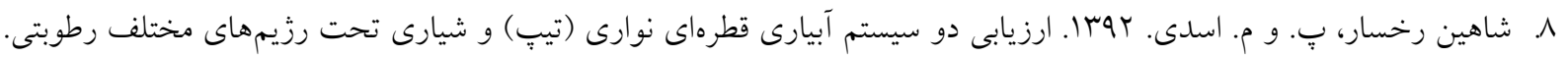

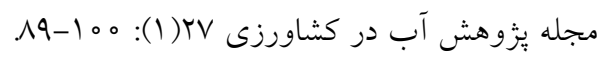

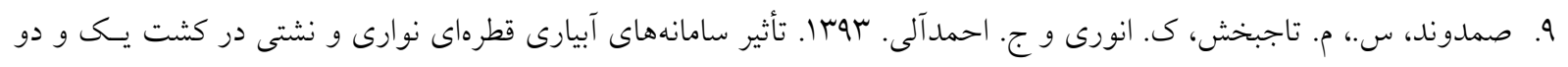

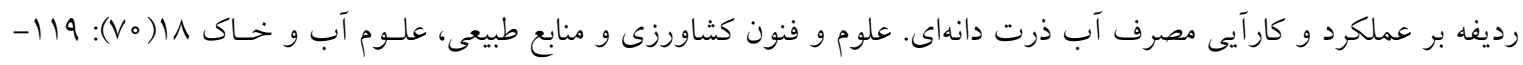




$$
\begin{aligned}
& \text { 11. عليز اده، ا. MM 11. اصول و عمليات آبيارى قطرهاى. انتشارات دانشكده كشاورزى دانشخاه امام رضا (ع). مشهد. }
\end{aligned}
$$

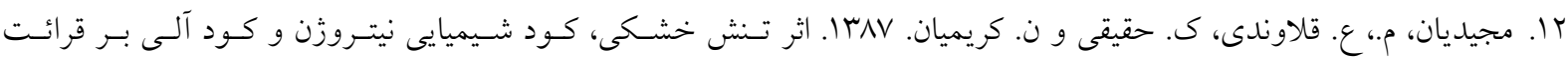

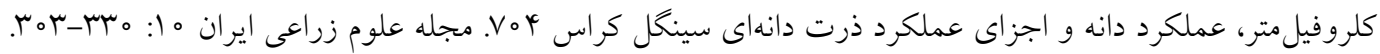

13. Ayars, J. E., R. B. Hutmacher, S. S. Vail and R. A. Schoneman. 1991. Cotton response to nonuniform and varying depts of irrigation. Agric. Water Manage. 19(2): 151-166.

14. Bronson, K. F., A. B. Onken, J. W. Keeling, J. D. Booker and H. A. Torbert. 2001. Nitrogen response in cotton as affected by tillage system and irrigation level. Soil Sci. Soc. Am. J. 65: 1153-1163.

15. Cakir, R. 2004. Effect of water stress at different development stages on vegetative and reproductive growth of corn. F. Crop Res. 89(1): 1-16.

16. Cetin, O. and L. Bilget. 2002. Effects of different irrigation methods on shedding and yield of Cotton. Agr. Water Manage. 54(1): 1-15.

17. Cheong Y. H., K. N. Kim, G. K. Pandey, R. Gupta, J. J. Grant and S. Luan. 2003. Calcium sense that differentially regulates salt, drought, and cold responses in Arabidopsis. The Plant Cell. 15(8): 1833-1845.

18. Hernandez, B., E. C. Avila, J. J. Olan, J. F. Lopez and L. A. Navarro. 2010. Morphological quality of sweet corn (Zea mays L.) ears as response to soil moisture tension and phosphate fertilization in Campech, Mexico. Agr. Water Manage. 97(9): 1365-1374.

19. Howel, T. A., J. A. Tolk, A. D. Schneider and R Evett. 1998. Evapotranspiration, Yield and Water Use efficiency of corn hybrids in maturity. Agron. J. 90: 3-9.

20. Lamm, F. R. and T. P. Trooien. 2003. Subsurface drip irrigation for corn production: a review of 10 years of research in Kansas. Irrigation Sci. 22: 195-200.

21. Oktem, A., M. Simsek and A. G. Oktem. 2003. Deficit irrigation effects on sweet corn (Zea Mays saccharata strut) with drip irrigation system in a semi-arid region; I. Water Yield Relationship. Agr. Water Manage. 61(1): 63-74.

22. Osbornc, S. L., J. S. Schepers, D. Franas and M. R. Schlcmer. 2002. Use of spectral radiance to in-scason biomass and grain yield in nitrogen and water stressed corn. Crop Sci. 42:165-186.

23. Sander, J. Z. and W. G. M. Bastiaanssen. 2004. Review of measured crop water productivity values for irrigation wheat, rice, cotton and maize. Agr. Water Manage. 69(2): 115-133.

24. Shakarami, G. and M. Rafiee. 2009. Response of corn (Zea mays L.) to planting pattern and density in Iran. Am. Eurasian J. Agric. Env. Sci. 5(1): 69-73.

25. Shaozhong, K., S. Wenjuan and Z. Jianhua. 2000. An improved water use efficiency for maize grown under regulated deficit irrigation. F. Crop Res. 67(3): 207-2014. 


\title{
Evaluating the Effect of Different Levels of Deficit Irrigation and Partial Root-Zone Drying on the Yield and Water Productivity of Maize in Hajiabad
}

\author{
M. Shahsavari ${ }^{1}$, A. Rezaei Estakhroeih ${ }^{\star 2}$, M. Irandost $^{1}$ and A. Nashat ${ }^{1}$
}

(Received: Aug. 25-2016; Accepted: March 07-2017)

\begin{abstract}
With the increase of population, the optimal use of water resources is necessary. This study was carried out to evaluate the impact of different levels of irrigation on the yield, yield components and water productivity of corn using single and double row drip irrigation systems (Tubes type). . The experiment was conducted in a split plot design based on the randomized complete block design (RCBD) with three replications in 2012 in Hajiabad, Hormozgan Province. The treatments were comprised of three levels of irrigation as the main plot (100, 80 and 60\% water requirement) and two patterns of irrigating water pipe installation (normal and every other row) as a sub-plot of the design. The results showed that irrigating with the 80 percent water requirement, in comparison with full irrigation, increased the total yield by $1.4 \%$, the seed weight by $1.8 \%$, the number of seeds per row by $8.7 \%$, and the number of seed row per maize by $13 \%$. In spite of yield superiority in the pattern of normally irrigating water pipe installation (10055.56 kg ha-1), against every other row installation (9366.67 kg ha-1), water productivity was more in every other row installation (1.089 kg m3). Therefore, partial root-zone drying was recommended by the irrigation of the $80 \%$ plant water requirement for the maize in the region.
\end{abstract}

Keywords: Drip Irrigation, Yield Components, Optimizing water use, Partial Rootzone Drying, Tubes type.

1. Azad University of Kerman branch, Kerman, Iran.

2. Department of Water Engineering, Faculty of Agriculture, Shahid Bahonar University of Kerman, Kerman, Iran.

*: Corresponding Author, Email: abbasrezaei2@gmail.com 